\title{
INTERPRETAÇÃO SOBRE RELAÇÃO DA FILOSOFIA COM O CONHECIMENTO, A SOCIEDADE E A NATUREZA COM BASE EM FEYERABEND E SLOTERDIJK
}

\author{
Vagno Batista Ribeiro ${ }^{1}$ \\ ${ }^{1}$ Universidade do Vale do Rio dos Sinos (UNISINOS-RS), São Leopoldo, RS, Brasil. \\ Resumo: Este texto estabelece uma relação de diálogo entre o campo da filosofia, a sociedade e as bases teóricas de \\ Feyrabend e Sloterdijk. É um bibliográfico, estuturado a partir de leituras diversas. Ao final pode se constatar que a matriz \\ filosófica torna-se o "recipiente" discursivo para tornar as demais faces da realidade em categorias cognítivas ajustáveis à \\ vida contemporânea.
}

Palavras - chave: Filosofia. Conhecimento. Sociedade.

\begin{abstract}
This text establishes a dialogue relationship between the field of philosophy, society and the theoretical bases of Feyrabend and Sloterdijk. It is a bibliographic, structured from different readings. In the end, it can be seen that the philosophical matrix becomes the discursive "container" to turn the other faces of reality into cognitive categories adjustable to contemporary life.
\end{abstract}

Keywords: Philosophy. Knowledge. Societ

Como citar: RIBEIRO, V. B. Interpretação sobre relação da filosofia com o conhecimento, a sociedade e a natureza com base em Feyerabend e Sloterdijk. Revista Científica Novas Configurações - Diálogos Plurais, Luziânia, v. 1, n.1, p. 5862, 2020. https://doi.org/.10.4322/2675-4177.2020.008

\section{INTRODUÇÃO}

Matriz de todas as ciências, a filosofia como paradigma fundamental do conhecimento humano, implica às vezes uma confusão benigna que reflete a complexidade epistemológica. A relação que existe entre a filosofia e o conhecimento, a sociedade e a natureza implica mais do que uma leitura interdisciplinar, ou seja, a descoberta de novos núcleos gnoseológicos. Neste sentido, este artigo limita-se em destacar apenas algumas tendências atuais epistemológicas que enfatizam o poder da filosofia em aprofundar aspetos do conhecimento humano, da sociedade e da natureza.

A abordagem parcelar e essencialmente superficial do assunto é justificada também pela perspectiva sincrônica que nos proporciona a atualização da disciplina. Constituída como ciência autônoma na Antiguidade grega, a especulação filosófica atual demostra uma evolução para hibridização com as outras disciplinas. Assim, esta "consiliência" (O. WILSON) com as outras perspectivas sobre a experiência humana segue uma leitura evolucionista conforme qual um organismo vivo não pode ser entendido sem uma investigação complexa do seu meio ambiente. Seguindo esta linha de pensamento que metaforiza o caminho gnoseológico através do vivo na sua complexidade relacional, a filosofia penetra 
basicamente quase todas as disciplinas como modalidade de especular a experiência humana na sua dimensão evolutiva.

\section{DESENVOLVIMENTO}

O primeiro tópico que abordaremos, enfoca a relação da filosofia com o conhecimento humano, isto é, aquilo que chamamos de gnosiologia ou de epistemologia. Neste sentido, a questão é de saber como a filosofia pode contribuir ao progresso da ciência, ao conhecimento humano em geral. Segundo pensamento de Richard Rorty, o paradigma da gnosiologia situa-se numa metáfora da natureza que considera o conhecimento como um reflexo objetivo do mundo cuja "origem" indica algumas intuições na obra de Descartes, Locke e Kant. Mas hoje em dia, as tendências epistemológicas tendem para uma visão pluralista do mundo substitui o unívoco da razão positivista do conhecimento cientifico. Um dos precursores deste pluralismo gnoseológico atual é Henri Bergson que realçou a intuição como possibilidade de ultrapassar a univocidade do cientísmo positivista. Rudolf Carnap enfatiza também, através da análise da linguagem, a falta de sentido positivista dos termos metafísicos, num contexto estético que traz satisfações tanto como a música.

Mas a metafísica, como arquétipo de todo o pensamento filosófico, é também o arquétipo de todo o pensamento científico. Neste sentido, a afirmação de Sócrates que afirma qualquer ambição de conhecimento total ("sei que nada sei"), valida o aprofundamento do mistério no ato cognitivo, tanto como no caso do ato estético ou da experiência mística.

Ao longo do tempo, as teorias filosóficas sobre o conhecimento destacaram várias maneiras de abordar a cognição humana a partir dos "instrumentos" que podem abraçar o mundo e a sua realidade, seja de ordem da percepção (os empiristas como John Locke, David Hume), de raciocínio (os racionalistas como René Descartes, Karl Popper, Jules Vuillemin) ou da ordem metafísica (LUC FERRY). Mas seria interessante de realçar uma atitude epistemológica atual que adota uma posição caótica face a estas maneiras de conhecimento do mundo: o anarquismo epistemológico. Promovido pelas teses do austríaco Paul Feyerabend (1924-1994) no seu livro Contra o Método (1975), este "terrorismo epistemológico" nega a necessidade metodológica de abordar o conhecimento. Assim, a ciência pode fracassar seguindo etapas lógicas e rígidas do raciocínio, sendo preferido um pluralismo metodológico que obedece à complexidade do mundo atual. Esta perspectiva dadaísta corresponde, talvez por uma analogia forçada, à teoria do caos que, de fato dissimula uma ordem perfeita do universo, mas que não pode ser entendida pelo humano limitado pela sua percepção. Invalida-se, então, a ideologia cientifica como possibilidade de compreender a realidade:

[...] we have theories that work in restricted regions, we have purely formal attempts to condense them into a single formula, we have lots of unfounded claims (such as the claim that all of chemistry can be reduced to physics), phenomena that do not fit into the accepted framework are suppressed; in physics, which many scientists regard as the one really basic science, we have now at least three different points of view...without a promise of conceptual (and not only formal) unification (FEYERABEND,1987, p. 100) ${ }^{1}$.

Com certeza, qualquer esforço vanguardista acaba por se classificar a esta tendência de negar os conceitos abstratos de "verdade" ou "objetividade", implica às vezes impasses cognitivos. Neste sentido, Feyerabend não consegue imaginar a ciência nem reinada pela razão, nem pela não-razão, mas que pode ser aproximada ao mito. Como maneira de explicar o mundo, a perspectiva mitológica seria muito mais adequada ao humano do que a ciência que, ao longo do tempo, foi veiculada como instrumento do poder político com graves consequências a nível social. Esta perspectiva filosófica sobre o conhecimento denuncia a ciência como instrumento ideológico de manipulação social, mas também pode ser uma força de libertação, assim como é o caso da libertação social.

\footnotetext{
${ }^{1}$ Livre tradução: “[...] nós temos teorias que trabalham em regiões restritas, temos tentativas puramente formais para condensá-las em uma única fórmula, temos muitas alegações infundadas (como a alegação de que toda a química pode ser reduzida à física ), fenômenos que quando não se encaixam no quadro são suprimidos; em física, onde muitos cientistas consideram como uma ciência realmente básica, temos agora pelo menos três pontos de vistas diferentes... sem uma promessa de unificação conceitual (e não apenas formal)".
} 
De fato, Feyerabend tinha uma crítica de ordem mais formal, invalidando o discurso pedante e crítico da ciência. Neste aspecto, a linguagem seria um truque retórico para persuadir e validar uma teoria cientifica, sendo assim, o anarquismo epistemológico justificado em afirmar que não há demarcação entre a ciência e a pseudociência. A partir deste ponto de vista, relembramos que incidimos nos preliminares deste artigo, a uma visão evolucionista em relação a todas as disciplinas. Portanto, a filosofia segue, no caso de Feyerabend, também uma leitura evolucionista camuflada nesta atitude anárquica, caótica, relembrando que são as mutações, os "acidentes genéticos" que induzem o padrão de evolução. Assim, o conhecimento não pode ser reduzido às fórmulas rígidas, nem compreendido em teorias simples e paralisantes, mas deve seguir o rumo natural do pensamento humano, entre o racional e irracional, sem que esta oposição seja um obstáculo de investigação da realidade.

Nesta equação, entra apenas a ideia humanista de liberdade de escolha do indivíduo que promove o pluralismo metodológico ajustado de uma maneira flexível aos momentos sociais e políticos diferentes. O conhecimento universal não deve ignorar as clivagens culturais de cada comunidade e, por consequência, tem de ser acessível à sensibilidade artística e à ao idioleto específico de cada um. Esta visão epistemológica lembra da teoria da consciliência do sócio biólogo O. Wilson que, no seu livro Conscilience (1998), afirmava o futuro do conhecimento humano apenas nestes termos de unificação entre as ciências duras e as humanidades. Esta flexão entre a razão e a emoção pode explicar o fato de que uma teoria científica não pode ser refutada de uma maneira "binária". Assim os conceitos podem ser "resterritorializados" (Deleuze) em vários contextos culturais e sociais para adquirirem outros valores de "verdade" científica. Da mesma forma, o processo de migração conceitual pode ser validado numa leitura sincrônica ou diacrônica. Ironicamente, Feyerabend aponta para uma adesão em relação às teorias cientificas garantidas apenas pelas relações sociais que os científicos entretêm entre eles. Exige-se, então, uma democratização da ciência do poder do pedantismo dos grupos consagrados, para uma ciência alternando metodologias e teorias pouco hierarquizadas, ou a Ciência como Arte. A ordem cognitiva deve ser atribuída ao sistema complexo neuronal do humano, e não ao poder social refletido em metodologias ditatoriais. Destarte, a indisciplina cognitiva é necessária para um progresso real da ciência, mas também para um processo de democratização social. Assim, o anarquismo epistemológico promove a liberdade de pensamento e de expressão, rejeitando o elitismo intelectual que hierarquiza a sociedade. Mais do que isso, cancela-se o efeito sedutor das ideologias monopolizadoras que validam apenas algumas atividades em sociedade (por exemplo: a superioridade da medicina tradicional em relação às terapias alternativas), da autoridade intelectual que é institucionalizada (partidos políticos, igreja etc.), da transmissão obrigatória do conhecimento (a escola) e da objetivização do conhecimento que produz esquizofrenia social.

Tendo em conta estes pontos de vista, o anarquismo epistemológico constitui também uma especulação filosófica sobre a sociedade e as suas teorias sobre o poder político. Nesta equação, o conceito político do saber reconfigura uma visão do mundo liberal onde nem sequer a metodologia e a teoria não podem invalidar a essência humana que favorece mais o questionamento, do que as certezas. Apesar de tudo isso, as pessoas preferem as doutrinas epistemológicas que se focam nas certezas, pois esta atitude pode facilmente proliferar e juntar grupos de militantes que protegem a sobrevivência. A razão desta visão anárquica sobre o conhecimento não ter sucesso é nomeadamente este domínio infinito de dúvidas que desestabiliza a convivência intelectual baseada, principalmente, no protagonismo social. Negando o "casamento" entre o estado e a ciência, Paul Feyerabend propõe uma organização social que segue o modelo de livre arbitro epistemológico que não favorece de uma forma constante e perseverante modelos ideológicos. Neste sentido, a anarquia epistemológica indica o caminho da versatilidade social e política também. O indivíduo pode ser subversivo contra o estado, atacando primeiro o dogma científico e a sua homogeneidade ideológica.

A nossa escolha por um autor como Paul Feyerabend foi feita pela dupla razão de apresentar um filósofo que alcança tanto aspectos epistemológicos, como aspectos sociais e políticos. Continuando o nosso percurso questionando a relação entre a filosofia e a natureza, decidimos apresentar uma nova perspectiva, a biosofia, desenvolvida pelo filósofo alemão contemporâneo, Peter Sloterdijk na sua trilogia Esferas (2003, 2005, 2010). Imbricando aspectos antropológicos, políticos, topológicos, biológicos e ecológicos, o filósofo acha mais justificada substituir a apelação filosófica pela biosofia, considerando a filosofia, como forma de pensamento da antiga Europa, irremediavelmente esgotada:

La philosophie, en tant que forme de pensée et de vie de l'ancienne Europe, est indéniablement épuisée ; la biosophie vient tout juste d'entamer son travail ; [...] la théorie générale des systèmes immunitaires et des systèmes communs en est à ses 
débuts ; une théorie des lieux, des situations, des immersions se met timidement en marche (SLOTERDIJK, 2005, p. 19). ${ }^{2}$

Este novo paradigma de pensamento filosófico enfatiza o meio e a sua ecologia que predetermina a vida dos seres e a interação entre eles. Neste quadro de reflexão ${ }^{3}$, a vida humana é redefinida por uma multiplicidade de aspectos biofísicos, sociais, técnicos, culturais que se imbricam numa leitura complexa evolucionista. Assim, o humano é surpreendido na sua capacidade atual de sobrevivência a partir das teorias gerais dos sistemas imunitários: ${ }^{4}$

Le thème du siècle émerge de la catastrophe de la culture traditionnelle et de sa morale holiste: Making the immun system explicit. Il pourrait être clair, d'emblée, que la construction de l'immunité est un évènement beaucoup trop global, beaucoup trop contradictoire pour qu'on puisse le décrire à l'aide des seules catégories médicobiochimiques: conformément à la complexité de sa nature, des composantes politiques, militaires, juridiques, religieuses, relevant de la technique de l'assurance et de la psychosémantique, entrent en jeu dans son déploiement dans le réel. Le crépuscule de l'immunité détermine l'éclairage intellectuel sur le XX e siècle (SLOTERDIJK, 2005, p. 174) $)^{5}$.

Neste sentido, no livro Tu dois changer la vie (2009), o Autor invoca a força do sistema imunitário social que possa garantir a sobrevivência frente a uma catástrofe mundial através do sistema da solidariedade e do sistema simbólico. Neste sentido, Sloterdijk fala de uma viragem pós-estruturalista em biologia:

\begin{abstract}
Ce n'est pas seulement par leur complexité que les systèmes immunitaires émergés troublent l'exigence de sécurité de leurs détenteurs: ils déconcertent plus par leur paradoxe immanent. Leur succès, lorsqu'ils sont trop radicaux, se renversent pour devenir des motifs de maladie d'un type spécifique: l'univers en croissance des pathologies auto-immunes illustre la tendance dangereuse qu'a le spécifique à obtenir sur lui-même une victoire à mort dans le combat contre l'Autre. Ce n'est pas par hasard si l'on voit se dessiner dans les interprétations récentes du phénomène de l'immunité une tendance à attribuer à la présence de l'Étranger un rôle beaucoup plus important qu'on le prévoyait dans les conceptions identitaires traditionnelles, celles d'un Soi constitué en organisme et fermé de manière monolithique - on pourrait littéralement parler d'un tournant poststructuraliste en biologie (SLOTERDIJK, 2005, pp. 176-177)
\end{abstract}

Prosseguindo nesta linha de pensamento do que Deleuze foi precursor, Sloterdijk considera, no seu estudo Regras para o Parque Humano, esta indeterminação homem-animal como um fracasso do homem no que respeita à aquisição do seu estatuto de animalidade: "Poderíamos até ir ao ponto de definir o humano como o ser que fracassou no seu ser-animal e no seu manter-se-animal. Graças ao seu fracasso como animal, o ser indeterminado escapa ao seu ambiente e ganha assim o mundo em sentido ontológico" (SLOTERDIJK, 2007, p. 51).

\title{
3 CONSIDERAÇÕES FINAIS
}

Sobrevoado de uma forma superficial o impacto que a filosofia pode ter em relação ao conhecimento, à sociedade e à natureza, optamos por dois autores contemporâneos que ultrapassam a abordagem interdisciplinar e transdisciplinar no sentido de uma visão holística sem que nenhuma das disciplinas tenha protagonismo dogmático. Mesmo que estes pensadores sejam considerados principalmente filósofos, a abordagem dos outros campos de conhecimentos de uma forma "rizómatica" (DELEUZE) indica todos os tópicos de interesse como centros de especulação cognitiva. Neste caso, a

\footnotetext{
${ }^{2}$ Livre tradução: “A filosofia, como uma forma de pensamento e de vida da velha Europa, é inegavelmente esgotada; a biosophie acaba de começar seu trabalho; [...] A teoria geral dos sistemas imunes e sistemas de união está em sua infância; a teoria dos lugares, situações, mergulhos começa timidamente em execução".

3 “Qu'est-ce que l'histoire du monde, si ce n'est aussi et toujours l'histoire de la guerre des systèmes immunitaires ?" (Sloterdijk, 2002:74).

${ }^{4}$ Foi nesta conjuntura que o filósofo alemão Sloterdijk reinterpretou (numa trilogia) a filosofia do espaço íntimo da existência humana a partir da esfereologia ou tratado de imunologia.

${ }^{5}$ Livre tradução: O tema do século emerge do desastre da cultura tradicional e de sua moral holística: Fazendo o sistema imunológico explícito. Pode ser claro desde o início que a construção de imunidade é um evento global muito, muito contraditório para nós para descrevê-lo usando apenas as categorias médicas e bioquímicas de acordo com a complexidade da sua natureza da política, militar, jurídica, religiosa, ao abrigo do seguro técnica e físicosemantico, estão envolvidos em implantação no real. Imunidade Crepúsculo determina a luz intelectual no século X”.
} 
matriz filosófica torna-se o "recipiente" discursivo para tornar as demais faces da realidade em categorias cognítivas ajustáveis à vida contemporânea.

\section{REFERÊNCIAS}

FEYERABEND, Paul (1975), Against Method: Outline of an Anarchistic Theory of Knowledge,

Minneapolis, University of Minnesota Press.

FEYERABEND, Paul (1987), Farweell to Reason, London, Verso.

SLOTERDIJK, Peter (2002), Sphères I. Bulles. Microsphérologie, Paris, Pauvert, Tradução: Olivier

Mannoni.

SLOTERDIJK, Peter (2007), Regras para o Parque Humano, Coimbra, Angelus Novus, Tradução:

Manuel Resende.

SLOTERDIJK, Peter (2010), Sphères II. Globes, Paris, Meta-Éditions, Tradução: Olivier Mannoni.

SLOTERDIJK, Peter (2013), Sphères III. Écumes. Sphérologie plurielle, Paris, Meta-Éditions, Tradução:

Olivier Mannoni.

SLOTERDIJK, Peter (dir.), Tu dois changer ta vie [Du musst dein Leben ändern, Frankfurt am Main,

Suhrkamp Verlag, 2009], O. Mannoni (trad.), Paris, Libella/M. Sell, 2011.

WILSON, Edward O. (1998), Consilience: the Unity of Knowledge, New York, Alfred A. Knopf.

\section{Informações sobre os autores:}

VBR: Doutorando da Universidade do Vale do Rio dos Sinos UNISINOS com tese: Educação, Identidade, Movimentos Sociais e Cidadania: práticas culturais e construção de identidades (início 2018.1). Professor Universitário dos seguintes Cursos de Graduação em Letras, Pedagogia, Matemática, Filosofia e Teologia e dos Cursos de Pós-Graduação Lato Senso das disciplinas: Sociologia da Educação, Sociologia Geral, Psicologia, Psicologia do Desenvolvimento, História da Educação, Ética, Filosofia da Educação, Estrutura do Currículo Educacional Fundamental, Médio e Superior, Antropologia, Diretos Humanos, Fundamentos Teóricos da Educação, Gêneros, Cultura e Diversidade. Mestre do Programa de Pós-Graduação Stricto Sensu em Teologia da Escola Superior de Teologia - EST/RS (CAPES - Conceito 6), LINHA DE PESQUISA - Educação Comunitária com Infância e Juventude, Mestre em Ciências Educacionais com área de concentração em Ensino e Currículo pela Universidade Evangélica. Especialista em Direitos Humanos (UCB), Especialista nos Cursos de: Docência do Ensino Superior e Gestão e Orientação Educacional pela FATED. Licenciado em Filosofia e Bacharel em Teologia.

Contribuição dos autores: VBR: conceitualização, captação de recursos, supervisão, redação. 